Article

\title{
Grafting of Gallic Acid onto a Bioactive Ti6A14V Alloy: A Physico-Chemical Characterization
}

\author{
Martina Cazzola $^{1,+} \mathbb{\oplus}$, Sara Ferraris ${ }^{1,+}$, Enrico Prenesti ${ }^{2} \mathbb{D}$, Valentina Casalegno ${ }^{1}$ \\ and Silvia Spriano $1, *$ (D) \\ 1 Department of Applied Science and Technology, Politecnico di Torino, C.so Duca degli Abruzzi 24, \\ 10129 Torino, Italy; martina.cazzola@polito.it (M.C.); Sara.ferraris@polito.it (S.F.); \\ Valentina.casalegno@polito.it (V.C.) \\ 2 Department of Chemistry, Università degli Studi di Torino, Via Pietro Giuria 5, 10125 Torino, Italy; \\ enrico.prenesti@unito.it \\ * Correspondence: silvia.spriano@polito.it; Tel.: +39-1-1090-5768 \\ + These authors contribute equally to this paper.
}

Received: 2 April 2019; Accepted: 25 April 2019; Published: 3 May 2019

\begin{abstract}
Despite increasing interest in the use of natural biomolecules for different applications, few attempts of coupling them to inorganic biomaterials are reported in literature. Functionalization of metal implants with natural biomolecules could allow a local action, overcoming the issue of low bioavailability through systemic administration. In the present work, gallic acid was grafted to a pre-treated Ti6Al4V in order to improve its biological response in bone contact applications. The grafting procedure was optimized by choosing the concentration of gallic acid $(1 \mathrm{mg} / \mathrm{mL})$ and the solvent of the solution, which was used as a source for functionalization, in order to maximize the amount of the grafted molecule on the titanium substrate. The functionalized surfaces were characterized. The results showed that functionalization with Simulated Body Fluid (SBF) as solvent medium was the most effective in terms of the amount and activity of the grafted biomolecule. A key role of calcium ions in the grafting mechanism is suggested, involving the formation of coordination compounds formed by way of gallic acid carboxylate and $\mathrm{Ti}-\mathrm{O}^{-}$as oxygenated donor groups. Bioactive behavior and surface charge of the pre-treated Ti6Al4V surface were conserved after functionalization. The functionalized surface exposed a greater amount of $\mathrm{OH}$ groups and showed higher wettability.
\end{abstract}

Keywords: titanium; gallic acid; polyphenols; surface functionalization; metal implants

\section{Introduction}

Polyphenols are organic molecules attracting more and more interest within the scientific community and their application is studied in different fields like medicine, pharmacology, packaging, food conservation and cosmetics. Polyphenols have anti-inflammatory, antioxidant, anticancer and antibacterial effects [1-3]. They can also affect bone health, i.e., stimulating differentiation of healthy osteoblasts [4] and promoting the apoptosis of osteosarcoma cells [5]. These molecules are also able to influence bone density [6,7] and the in vitro deposition of hydroxyapatite [8,9].

Surface functionalization and coating with natural biomolecules is a material science emerging field: Some attempts of coupling polyphenols to biomaterials are reported in literature till now and they are briefly summarized below.

As far as nanoparticles functionalization is concerned, benzoic, caffeic, coumaric, ferulic and syringic acids from plant extracts were linked to magnetic nanoparticles using polyethylene glycol (PEG) as linker molecule [10]; quercetin was covalently linked to rare earth nanoparticles by means 
of silane [11]; resveratrol was coupled with gold [12], polycaprolactone [13] and polycaprolactone (PCL)/collagen nanoparticles [4] and gallic acid were encapsulated in zein electrospun nanoparticles [14]. Concerning nanostructured substrates, apple polyphenols were encapsulated in a $\beta$-cyclodextrin nanostructured sponge [15], rutine (present in plants such as those of the genus Citrus) was adsorbed on mesoporous silica mesostructured MCM-41 type [16] and polyphenols from green tea leaves were coupled with carbon nanotubes [17].

Considering polymers functionalization, the following biomolecules were grafted to fibers, films or microspheres of chitosan: Flavonoids (by means of the tyrosine kinase enzyme) [18], quercetin, tannic acid (by means of laccase enzyme) [19], caffeic acid [20], thyme polyphenols [21], Zataria multiflora Boiss essential oil, extract of grape seeds [22], raspberry leaf, hawthorn, ivy, yarrow, nettle and olive leaves [23]. Curcumin was physically encapsulated in polyurethane membranes [24]. Epigallocatechin gallate (EGCG) was used for functionalization of collagen fibers [25] while extract of coriander was physically encapsulated in a bone graft material (biphasic calcium phosphate and casein chitosan) [26].

Few researches considered inorganic materials as substrates for functionalization: Extract of Gusuibu (Drynaria roosii) was covalently linked to calcium hydrogen phosphate [27]; natural polyphenols and pyrogallol were used as coating on stainless steel [28]. Silica-based bioactive glasses and glass ceramics were successfully functionalized with gallic acid and natural extracts from red grape skins and green tea leaves by the authors, as reported in previous papers $[29,30]$.

New protocols for functionalization have to be developed if we change the substrate moving towards titanium alloys. Surface modifications of titanium and its alloys, in order to confer bioactive and antibacterial properties, are widely studied [31-33], but papers related to functionalization with natural biomolecules are very few in number. The following biomolecules were coupled to titanium or titanium dioxide substrates: Natural polyphenols and pyrogallol [28], quercetin [34], taxifolin [35], rhamnogalacturonan-Is (RG-Is) isolated from potatoes and apples [36], lignin [37] and gallic acid esters (namely, octyl-, decyl-, lauryl- and cetyl-gallate) [38].

In this work, a surface functionalization protocol has been optimized (selection of solvent medium and $\mathrm{pH}$, effects of $\mathrm{Ca}^{2+}$ ions in solutions, concentration of the source solution) in order to graft a significant amount of gallic acid (GA) onto Ti6Al4V alloy surface, previously made bioactive through a specific chemical treatment. Gallic acid (3,4,5-trihydroxybenzoic acid) is used here as a model biomolecule for polyphenols. It shows antioxidant, neuroprotective and antitumor abilities $[39,40]$. A preliminary characterization of the functionalized surfaces was performed by means of the Folin-Ciocalteu photometric test and XPS (X-ray Photoelectron Spectroscopy) analysis, to verify the presence and activity of the grafted GA. The in vitro bioactivity of the samples was investigated by soaking in Simulated Body Fluid (SBF). Surface wettability and surface charge were evaluated by means of contact angle and zeta potential measurements, respectively.

\section{Materials and Methods}

\subsection{Surface Activation}

Ti6Al4V disks (2 mm in thickness, $10 \mathrm{~mm}$ diameter, ASTM B348 [41], Gr5, Titanium Consulting and Trading) were polished with $\mathrm{SiC}$ paper (up to 4000 grid) and washed in an ultrasonic bath (5 $\mathrm{min}$ in acetone and twice $10 \mathrm{~min}$ in ultrapure water).

In order to induce bioactive behavior and high density of hydroxyl groups on the surface, suitable for the further surface functionalization, the titanium substrate underwent a specific patented chemical treatment [42,43]. It includes a first acid etching in hydrofluoric acid and a subsequent controlled oxidation. After this treatment, the samples were exposed for $1 \mathrm{~h}$ to $\mathrm{UV}$ in order to make the surface more reactive [44]. From now on, the samples treated as above described will be named as "chemically-treated-CT". 


\subsection{Surface Functionalization}

Gallic acid (3,4,5-Trihydroxybenzoic acid, GA, 97.5-102.5\% titration, G7384, Sigma-Aldrich, St. Louis, MO, USA) was employed for functionalization as model molecule for polyphenols. This molecule was selected because of its simple structure and extensive literature available on it.

For surface functionalization, source solutions with two different concentrations of the biomolecule ( 1 and $2 \mathrm{mg} / \mathrm{mL}$ ) in 3 media (namely, ultrapure water-W, Phosphate Buffered Saline-PBS and Simulated Body Fluid-SBF) were prepared. PBS (PBS, Sigma-Aldrich, P4417) was prepared by dissolving 1 tab (2 g) in $200 \mathrm{~mL}$ of ultrapure water, while SBF was prepared according to the protocol described by Kokubo [45].

Each sample, after the above described chemical treatment and UV irradiation (CT), was put in a holder with $5 \mathrm{~mL}$ of the selected GA solution in the dark for $8 \mathrm{~h}$ at $37^{\circ} \mathrm{C}$. After the incubation, the samples were washed two times with a quick immersion in ultrapure water, dried at room temperature and preserved in the dark. The nomenclature of the source solutions and of the functionalized samples is reported in Table 1.

Table 1. Acronyms and a brief description of the source solutions and of the functionalized samples.

\begin{tabular}{cc}
\hline Sample Acronym & Sample Description \\
\hline WATER + GA_1 & Solution $1 \mathrm{mg} / \mathrm{mL}$ of Gallic acid in ultrapure water \\
WATER + GA_2 & Solution $2 \mathrm{mg} / \mathrm{mL}$ of Gallic acid in ultrapure water \\
SBF + GA_1 & Solution $1 \mathrm{mg} / \mathrm{mL}$ of Gallic acid in SBF \\
SBF + GA_2 & Solution $2 \mathrm{mg} / \mathrm{mL}$ of Gallic acid in SBF \\
PBS + GA_1 & Solution $1 \mathrm{mg} / \mathrm{mL}$ of Gallic acid in PBS \\
PBS + GA_2 & Solution $2 \mathrm{mg} / \mathrm{mL}$ of Gallic acid in PBS \\
CT & Ti6Al4V sample chemical treated and UV irradiated \\
CT_GA_W_1 & CT sample functionalized with solution $1 \mathrm{mg} / \mathrm{mL}$ of Gallic acid in ultrapure water \\
CT_GA_W_2 & CT sample functionalized with solution $2 \mathrm{mg} / \mathrm{mL}$ of Gallic acid in ultrapure water \\
CT_GA_SBF_1 & CT sample functionalized with solution $1 \mathrm{mg} / \mathrm{mL}$ of Gallic acid in SBF \\
CT_GA_SBF_2 & CT sample functionalized with solution $2 \mathrm{mg} / \mathrm{mL}$ of Gallic acid in SBF \\
CT_GA_PBS_1 & CT sample functionalized with solution $1 \mathrm{mg} / \mathrm{mL}$ of Gallic acid in PBS \\
CT_GA_PBS_2 & CT sample functionalized with solution $2 \mathrm{mg} / \mathrm{mL}$ of Gallic acid in PBS \\
\hline
\end{tabular}

\subsection{Detection of the Grafted Biomolecule}

The presence and activity of GA on the surface of the functionalized samples were investigated by means of the Folin-Ciocalteu test (F\&C) and by means of X-ray Photoelectron Spectroscopy (XPS).

The F\&C test measures the redox reactivity of phenolic substances and give a quantification of their amount using a calibration curve obtained with GA as standard [29]. The test was performed on the source solution (before and after functionalization) and on the functionalized samples as reported in previous works $[29,30,46]$. This analysis was performed in triplicate and statistical analysis was obtained through ANOVA one-way test $(p<0.05)$.

As far as XPS analyses (XPS, PHI 5000 VERSAPROBE, Physical Electronics, Chigasaki, Japan) are concerned, both the survey spectra and high-resolution analyses of carbon and oxygen regions were performed to determine the chemical composition of the surface, the elemental chemical state of and to identify the functional groups exposed on the surface. The results were used to define the best functionalization medium and the best concentration of the source solution for optimization of the functionalization protocol.

\subsection{Contact Angle Measurements}

In order to evaluate surface wettability, contact angle measurements were performed by the sessile drop method before and after functionalization with ultrapure water. A heating microscope (Misura ${ }^{\circledR}$, Modena, Italy, Expert System Solutions) at room temperature, was used for the acquisition of images and the contact angle value was obtained by images elaboration with Image J (version 1.47) software. 


\subsection{In Vitro Apatite-Forming Ability Tests (Bioactive Behavior)}

The apatite-forming ability of the samples before and after functionalization was investigated by soaking the samples in SBF. Two specimens for each type of sample were soaked in the dark in $25 \mathrm{~mL}$ of SBF, prepared according to the protocol developed by Kokubo and Takadama [47], at $37^{\circ} \mathrm{C}$ up to 28 days.

2.6. Field Emission Scanning Electron Microscopy (FESEM) Observations and Energy Dispersive Spectroscopy (EDS) Analyses

After soaking in SBF, eventual deposition of hydroxyapatite on the surfaces was observed by means of Field Emission Scanning Electron Microscopy equipped with Energy Dispersive Spectroscopy (FESEM-EDS SUPRATM 40, Zeiss and Merlin Gemini Zeiss, Cohen, Germany). Samples have been observed without metallization.

\subsection{Electro-Kinetic Measurements}

The zeta potential of the samples in function of $\mathrm{pH}$ was analyzed by means of electro-kinetic measurements (SurPASS, Anton Paar, Graz, Austria) using $0.001 \mathrm{M} \mathrm{KCl}$ as electrolyte. Basic and acid titrations are two separate measurements performed varying the $\mathrm{pH}$ by the addition of $0.05 \mathrm{M} \mathrm{HCl}$ or $0.05 \mathrm{M} \mathrm{NaOH}$, respectively, through the automatic titration unit of the instrument.

\section{Results and Discussion}

\section{1. $p H$ Measurements}

The $\mathrm{pH}$ values of the solutions before (source solutions) and after (uptake solutions) the procedure of functionalization were measured and the color was observed (Table 2).

Table 2. $\mathrm{pH}$ values of the source and uptake solutions.

\begin{tabular}{ccc}
\hline Solution & $\mathbf{p H}$ & Color of the Solution \\
\hline WATER + GA_1 & $3.35 \pm 0.04$ & Colorless \\
(Source) & & \\
WATER + GA_2 & $3.17 \pm 0.04$ & Colorless \\
(Source) & $7.45 \pm 0.10$ & Blue \\
SBF + GA_1 (Source) & $7.10 \pm 0.11$ & Blue \\
SBF + GA_2 (Source) & $6.17 \pm 0.09$ & Colorless \\
PBS + GA_1 (Source) & $4.60 \pm 0.12$ & Colorless \\
PBS + GA_2 (Source) & $3.36 \pm 0.01$ & Colorless \\
WATER + GA_1 (Uptake) & $3.15 \pm 0.04$ & Light yellow \\
WATER + GA_2 (Uptake) & $7.22 \pm 0.04$ & Blue \\
SBF + GA_1 (Uptake) & $6.71 \pm 0.08$ & Blue \\
SBF + GA_2 (Uptake) & $6.05 \pm 0.07$ & Light yellow \\
PBS + GA_1 (Uptake) & Colorless \\
PBS + GA_2 (Uptake) & $4.49 \pm 0.04$ &
\end{tabular}

The $\mathrm{pH}$ values and color are significant parameters for the solutions containing polyphenols, because they give a first indication of the chemical state of the biomolecules. The electronic absorption spectra of polyphenols are strongly dependent on the medium used for their dissolution, the presence of electro-donating of electron-withdrawing substituents such as metal ions and formation of a $\mathrm{pH}$ dependent resonance form [48].

In order to allow the binding of a significant amount of biomolecules to the surface, the protocol of functionalization used in this research was developed from previous works of the authors $[29,30]$ and from literature data [28]. The previous works of the authors concern surface functionalization of bioactive glasses and glass ceramics. A protocol of functionalization was elaborated over time in order to optimize grafting of the biomolecules on the glasses avoiding degradation of the biomolecules 
themselves. In the case of bioactive glasses, the main issue is the regulation of $\mathrm{pH}$ avoiding a too strong alkalization induced by massive ion release from bioactive glasses in water-based media. This work is focused on titanium surfaces and a different protocol must be developed.

In this case, ion release from the substrate into water-based media is almost negligible and consequently $\mathrm{pH}$ of the functionalization solution during sample soaking remains close to the initial one. In this case, in order to maximize the reactivity of polyphenols and their ability to be bond to the surface, both $\mathrm{pH}$ and ionic composition of the solution should be optimized in order to favor surface grafting. This specific point is the topic of the present research work.

The source water solutions of GA were slightly acidic ( $\mathrm{pH}$ is around 3) and they did not change in a significant way after incubation of the samples. These solutions were colorless, due to the acidic $\mathrm{pH}$ and the absence of metal cations (necessary for the formation of colored complexes with GA) [48,49]. The uptake solution WATER + GA_2 evidenced a slight change of color, turning from colorless to light yellow. This phenomenon can be associated with the release of few $\mathrm{Ti}^{4+}$ ions in the solution and the consequent formation of gallic acid titanium complexes which can be yellow colored [50]. Within this range of $\mathrm{pH}$, deprotonation of GA is not enhanced significantly. PBS and SBF were utilized as alternative media for the source solutions of GA in order to perform functionalization at $\mathrm{pH}$ values higher than 4: Pure PBS and SBF media have both a $\mathrm{pH}$ value of 7.40 [51,52]. At this $\mathrm{pH}$, deprotonation of the carboxylic group of the biomolecule is induced and grafting to the surface can be improved [53]. However, $\mathrm{pH}$ of the source solution should not be higher than 10 to avoid immediate and irreversible oxidative degradation (shift from phenol to quinone groups) of GA. It is also important to set and control the time of incubation, because a long permanence at $\mathrm{pH}$ values exceeding 7.40 leads to a slow degradation of the molecule [48].

For the PBS solutions, the pH values of the source solutions PBS + GA_1 and PBS + GA_2 were 6.17 and 4.60 respectively and they remained almost unchanged in the uptake solutions. The source PBS + GA solutions were colorless, which can be attributed both to $\mathrm{pH}$ which was lower than 7.40 upon GA additions, and to the absence of metal cations $[48,49]$. For the uptake solution with $1 \mathrm{mg} / \mathrm{mL}$ of GA (Uptake PBS + GA_1), a light-yellow color appeared after functionalization: This was not completely unexpected, because a small oxidative degradation of gallic acid can be caused by a number of environmental factors. It must be also underlined that PBS did not have an effective buffer action on $\mathrm{pH}$ and a clear trend in behavior of PBS solution was not observed.

In the SBF solutions, the deprotonation of carboxylic acid was also improved by the presence of calcium cations that were not present in PBS solution. The source solution SBF + GA_2 showed a slight decrease of $\mathrm{pH}$ down to 7.10 with respect to pure SBF because of the addition of GA. The source and uptake solutions with a GA concentration of $2 \mathrm{mg} / \mathrm{mL}$ show a higher decrease of $\mathrm{pH}$ : This was due to the tendency of GA, which was present in a higher amount, to dissociate, producing $\mathrm{H}^{+}$ions.

All the solutions of GA in SBF were blue because of the deprotonation of the carboxylic group and the tendency of the polyphenols to form complexes with metal cations (e.g., $\mathrm{Ca}^{2+}$ ). The investigation of the role of calcium in functionalization of surfaces with polyphenols was as first preliminary performed by using a simple water medium containing only $\mathrm{CaCl}_{2}$ (with $\mathrm{Ca}^{2+}$ ions in the same concentration of SBF), a solution of buffer (Tris(hydroxymethyl)aminomethane (TRIS)/HCl) and a solution containing both. It has been observed that the presence of $\mathrm{Ca}^{2+}$ ions is crucial for GA binding on CT surfaces. In fact, the use of a buffer (TRIS/HCl) without $\mathrm{Ca}^{2+}$ is not sufficient for an effective functionalization (unpublished results). The preliminary test performed evidenced a blue coloration of the functionalization solution prepared with $\mathrm{CaCl}_{2}$ and TRIS/ $\mathrm{HCl}$ buffer which suggest the formation of GA-Ca ${ }^{2+}$ complexes in the solution. The first functionalization trial of CT surfaces with these solutions suggests a crucial role of GA-Ca ${ }^{2+}$ complexes for an effective grafting of GA to titanium surfaces and it was investigated in details in this work.

The time of incubation is a constant throughout this work $(8 \mathrm{~h})$ and it was selected as a compromise among different issues: Maximization of the amount of the grafted biomolecule, reasonable process time, avoiding corrosion of the substrate in the case of source solutions prepared with water as medium 
( $\mathrm{pH}$ around 3) and avoiding degradation of the biomolecule at physiological $\mathrm{pH}$ (close to 7.4) in the case of source solutions prepared with PBS and SBF as media.

\subsection{Biomolecule Detection}

Figure 1a shows the concentration of GA in the source solutions quantified by way of the F\&C test. The values obtained were comparable with the nominal concentrations, confirming that GA was stable in the chosen solvents, at least for the time necessary for the selected protocol. Only the solution PBS + GA_2 shows a concentration lower than the nominal one and it could indicate an initial degradation of the biomolecule not evidenced by a color change. The analyses on the uptake solutions did not highlight a significant lowering of the concentration of GA compared to that of the source solutions: The amount of the grafted GA was too low to be detected by this way. The photometric analyses performed on the functionalized samples showed the presence of GA on all the surfaces. As first, the tendency of the polyphenols to bind to the surfaces exposed to aqueous solutions reported in literature was confirmed [28,54].

a)

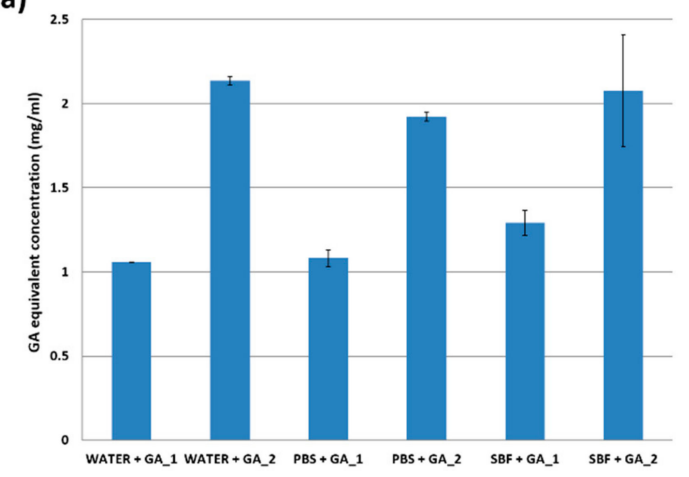

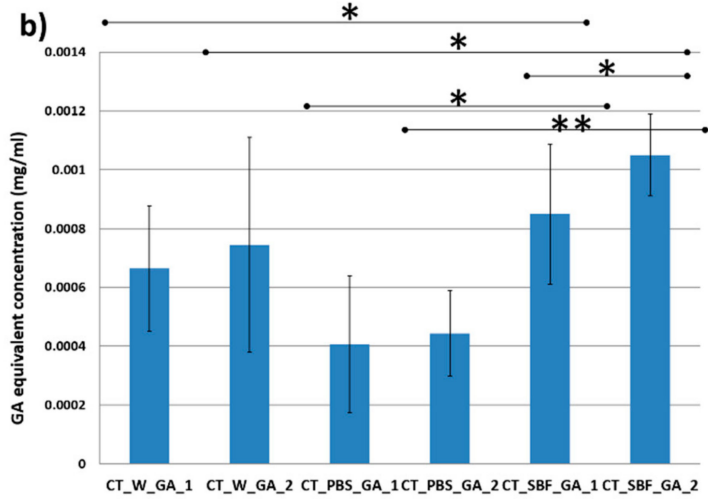

Figure 1. Results of the Folin-Ciocalteu test for quantification of gallic acid in (a) source solutions and on (b) functionalized samples $\left({ }^{*} p<0.05,{ }^{* *} p<0.5\right)$.

Figure $1 \mathrm{~b}$ highlights a statistically significant greater amount of GA grafted on the samples functionalized in SBF + GA with respect to the samples WATER + GA and the samples PBS + GA $(p<0.05)$ comparing the samples treated with the same GA concentration. The difference of polyphenol concentration on the surfaces treated with the two different concentrations of GA in the same solvent has a low statistical significance $(p>0.05)$. This observation suggests that, in the reported functionalization conditions, the surface reactive sites, available for GA grafting, are almost completely saturated upon contact with $1 \mathrm{mg} / \mathrm{mL}$ solutions.

The atomic percentages of the elements detected on the surface of the Ti6Al4V samples by means of XPS survey analyses, after functionalization from different source solutions, are reported in Table 3.

Table 3. Atomic percentages of the elements detected on the samples by XPS survey analyses.

(Uncertainty of measurements 0.5 at. $\%-1$ at.\%).

\begin{tabular}{|c|c|c|c|c|c|c|c|}
\hline \multirow{2}{*}{$\begin{array}{r}\text { Elements } \\
\text { [at.\%] }\end{array}$} & \multicolumn{7}{|c|}{ Samples } \\
\hline & CT & $\begin{array}{c}\text { CT_GA_ } \\
\mathbf{W}_{-} \mathbf{1}\end{array}$ & $\begin{array}{c}\text { CT_GA_ } \\
\mathbf{W} \_2\end{array}$ & $\begin{array}{c}\text { CT_GA_ } \\
\text { PBS_1 }\end{array}$ & $\begin{array}{c}\text { CT_GA_ } \\
\text { PBS_2 }\end{array}$ & $\begin{array}{c}\text { CT_GA_ } \\
\text { SBF_1 }\end{array}$ & $\begin{array}{c}\text { CT_GA_ } \\
\text { SBF_2 }\end{array}$ \\
\hline $\mathrm{O}$ & 57.0 & 52.6 & 49.6 & 59.0 & 55.5 & 44.7 & 47.8 \\
\hline C & 19.0 & 29.9 & 31.8 & 19.1 & 20.2 & 45.2 & 39.1 \\
\hline $\mathrm{Ti}$ & 18.2 & 15.9 & 14.9 & 15.6 & 15.6 & 6.6 & 8.7 \\
\hline $\mathrm{Ca}$ & - & - & - & 0.8 & - & 3.5 & 3.2 \\
\hline Others & 5.8 & 1.6 & 3.8 & - & 5.4 & - & 8.7 \\
\hline
\end{tabular}

A certain amount of carbon can be detected on the CT samples due to unavoidable contaminations on the titanium surfaces [55]. A moderate increase of the carbon content can be observed on the 
samples functionalized in water solutions (CT_GA_W_1 and CT_GA_W_2) and a higher one on the samples functionalized in SBF solutions (CT_GA_SBF_1 and CT_GA_SBF_2). On the other hand, a negligible variation of the surface carbon content can be detected on the samples functionalized in PBS (CT_GA_PBS_1 and CT_GA_PBS_2). The increase of the surface carbon can be correlated to grafting of GA and the results are in agreement with the results of the Folin-Ciocalteu test.

A not negligible amount of calcium ion was detected on the samples functionalized in SBF (CT_GA_SBF_1, CT_GA_SBF_2) while negligible amount of calcium ion was observed on one sample functionalized in PBS (CT_GA_PBS_1): In this case, due to the very low amount and absence in PBS solution (at least theoretically), it can be considered a contamination. The presence of calcium on the samples incubated in the source solutions with SBF as medium, can be related to the GA ability to bind this element $[8,30]$ within a complexation reaction $[49,56]$. It is reported $[48,56]$ that polyphenols are prone to give complexation reactions in solutions containing metal ions; the structure of the coordination compounds can be different depending on the $\mathrm{pH}$ of the solution. At $\mathrm{pH}$ values higher than 6 can be hypothesized that a heterogeneous ternary coordination compound is formed with the metal ions in a central position. The complex compound formation can involve both the carboxylate ion of $\mathrm{GA}$ and $\mathrm{Ti}^{-} \mathrm{O}^{-}$as donor groups. The formation of the coordination compound influences the chemical reactivity of polyphenols, for instance they are able to polymerize and to form coatings [56,57]: Particularly, in the present case it is shown that they were much more prone to be grafted on a surface. The possible formation of the complex and its binding to the surface is reported in Figure 2.

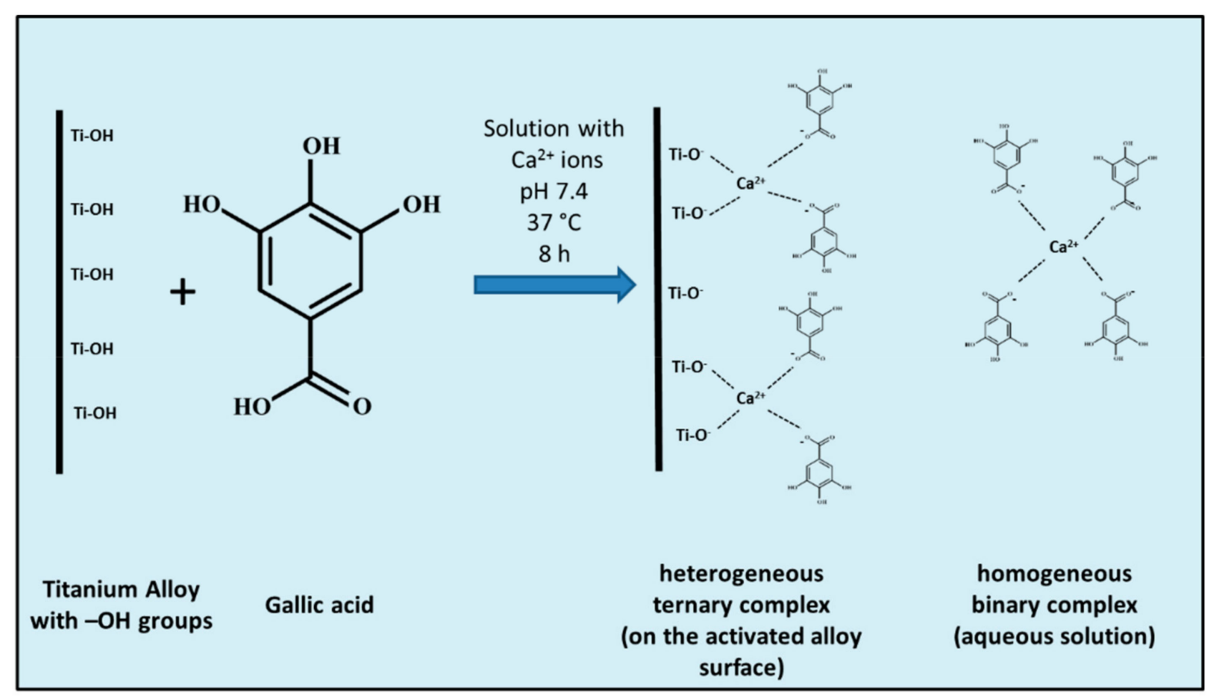

Figure 2. Scheme of the possible binding of gallic acid with the titanium alloy surface and Ca (II). Only the planar coordination is reported.

At $\mathrm{pH}$ 7.40, the GA (in the gallate chemical form, with the carboxylic group deprotonated) was bound to the alloy surface (in the $\mathrm{Ti}-\mathrm{O}^{-}$chemical form) having $\mathrm{Ca}^{2+}$ ion as linking species. A heterogeneous ternary complex was then probably formed, allowing the grafting of the gallate ion to the activated alloy surface). In the uptake solution, the excesses GA and free calcium ions could form homogeneous complexes (Ca(II)-gallate with different coordination numbers), in Figure 2 one of the possible planar coordination is reported, the eventual equatorial coordination and 3D structure is omitted. The presence of calcium ions could also allow a multistep assembly of polyphenols coordination obtaining a thicker layer of polyphenols grafted to the surfaces in order to meet the threshold concentration needed to induce beneficial effects on cells.

The ability of polyphenols to attract and bind calcium ions could have an influence also in the induced precipitation of hydroxyapatite during soaking in SBF (see Section 3.4) [56] as already observed by the authors in the case of surface functionalization of bioactive glasses with GA [30]. The absence of calcium in the PBS medium can explain the significantly lower amount of GA grafted on the surfaces 
exposed to source solutions prepared with this medium: The presence of a metal ion forming complex with polyphenols is crucial for their grafting.

The observation of the surface chemical composition gave some information, but it was not sufficient in order to determine the presence of the grafted biomolecule. In order to detect the specific functional groups of GA, a detailed analysis of the carbon and oxygen regions was performed and the results are reported in Figures 3 and 4.

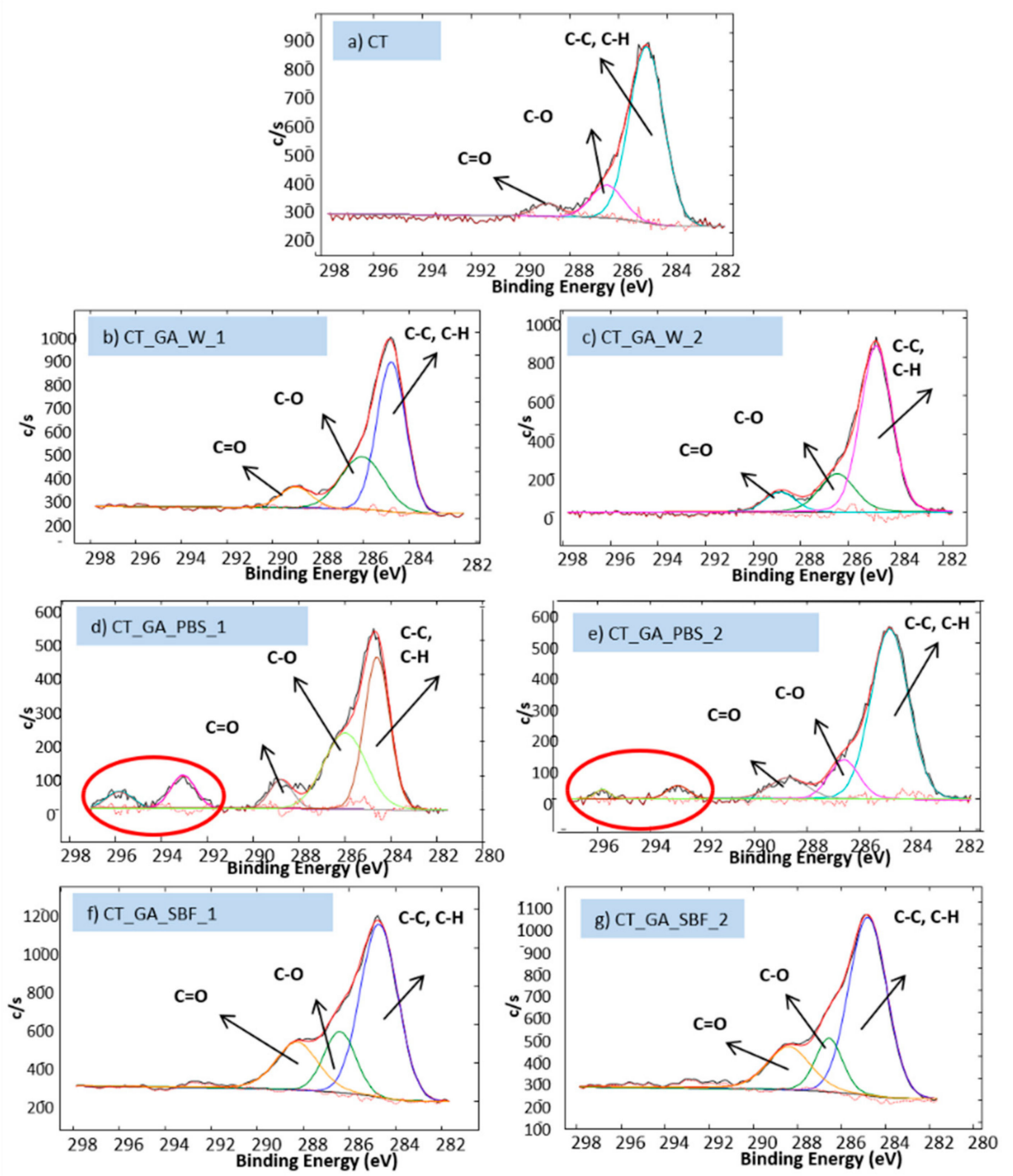

Figure 3. XPS high-resolution spectra of carbon region. (a) CT; (b) CT_GA_W_1; (c) CT_GA_W_2; (d) CT_GA_PBS_1; (e) CT_GA_PBS_2; (f) CT_GA_SBF_1; (g) CT_GA_SBF_2.

Looking at the high-resolution spectra of the carbon region of the CT samples (Figure 3a), the main signal at $284.81 \mathrm{eV}$ can be observed together with two small contributions at 286.26 and $289.17 \mathrm{eV}$. The signal at $284.81 \mathrm{eV}$ can be attributed to $\mathrm{C}-\mathrm{C}$ and $\mathrm{C}-\mathrm{H}$ bonds within hydrocarbon contaminants, always present on the titanium surfaces which are very reactive towards carbon and it was already detected by the authors [31]. The other two contributions respectively fall in the regions of $\mathrm{C}-\mathrm{O}$ and $\mathrm{C}=\mathrm{O}$ bonds $[57,58]$ : they have low intensities on this sample and are associated to surface contaminations [31]. The signal at $284.81 \mathrm{eV}$ is unchanged on the functionalized samples (Figure $3 \mathrm{~b}-\mathrm{g}$ ). On the other hand, a significant increase in the contributions at 286.26 and $289.17 \mathrm{eV}$ is evident for CT_GA_SBF_1 and CT_GA_SBF_2. As far as the signal at $284.81 \mathrm{eV}$ is concerned, C-C and C-H bonds are typical of the above-cited hydrocarbon contamination but are also present within the GA 
molecule. The presence of $\mathrm{C}-\mathrm{O}$ and $\mathrm{C}=\mathrm{O}$ can be associated with the presence of $\mathrm{GA}$ and to its tendency (phenol groups) to oxidize into quinone, as previously observed by the authors [29,30].

A further couple of signals at about 293 and $295.8 \mathrm{eV}$ can be observed on the samples functionalized in PBS (CT_GA_PBS_1 and CT_GA_PBS_2, Figure 3d,e). They can be associated to shake up satellite peaks due to aromatic rings $[59,60]$ and suggest a different disposition of GA molecules grafted on the titanium surfaces when PBS is used as medium for the source solutions. The different orientation of GA grafted on the surface after functionalization in PBS can be explained considering (i) the different $\mathrm{pH}$ value (in comparison with that of the source solutions prepared in water); and ii) the chemical composition, with the absence of the $\mathrm{Ca}^{2+}$ ion with its coordinating ability towards oxygen donor groups, (in comparison with that of the source solutions prepared using SBF as solvent). The different orientation of the grafted biomolecule can be related to the lower redox activity registered by the Folin \& Ciocalteu test on these surfaces.

The high-resolution spectra of the oxygen region are reported in Figure 4.
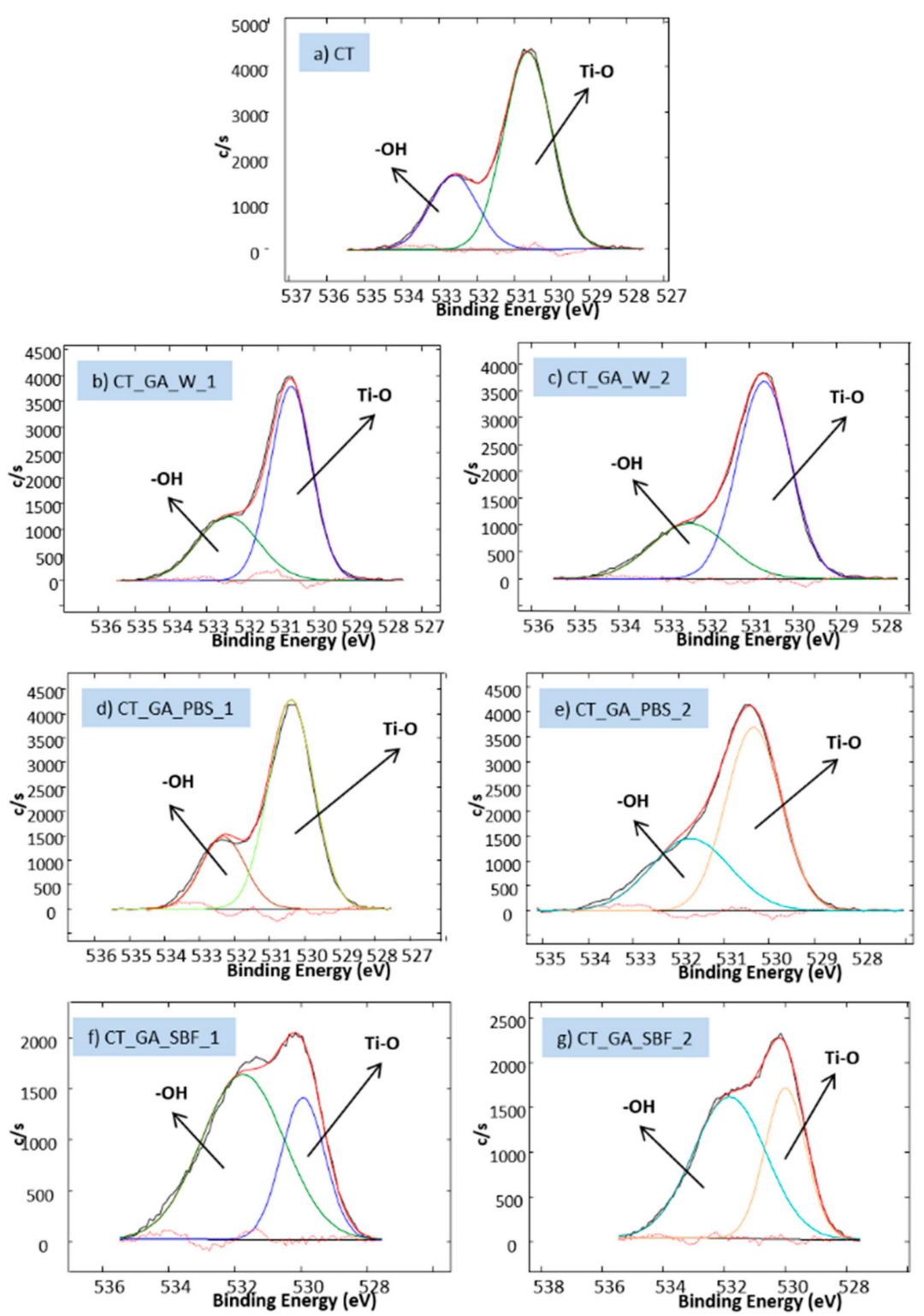

Figure 4. XPS high-resolution spectra of the oxygen region. (a) CT; (b) CT_GA_W_1; (c) CT_GA_W_2; (d) CT_GA_PBS_1; (e) CT_GA_PBS_2; (f) CT_GA_SBF_1; (g) CT_GA_SBF_2. 
Two signals around 530 and $532 \mathrm{eV}$ can be observed on all the samples. The first one can be attributed to oxygen within the Ti-O bonds in the titanium oxide layer, while the second one can be assigned to the $\mathrm{OH}$ groups [43]. $\mathrm{OH}$ groups are more abundant on the surface chemically treated (CT) samples than on pristine TI6Al4V alloy, as previously evidenced by the authors $[43,61,62]$. A further notable increase in the $\mathrm{OH}$ signal can be observed after GA grafting, mainly on the samples functionalized by using the source solutions with SBF as medium, and it can be explained considering that GA is rich in hydroxyl groups and they are still exposed after grafting. In the case of the samples functionalized in a source solution with PBS as medium, the lower amount of $\mathrm{OH}$ groups can be related both to a reduced amount of grafted biomolecule and to a different orientation on the surface. The growth of the $\mathrm{OH}$ peak after gallic acid functionalization was already observed by the authors on the functionalized bioactive glasses [29,30]. Since functionalization starting from source solutions with SBF as medium gave the best results in terms of amount and activity of grafted GA and that no highly significant $(p<0.05)$ differences were detected between the two tested concentrations, further analyses were performed only on the CT_GA_SBF_1 samples and on the CT samples as reference.

\subsection{Contact Angle Measurements}

The bar graph in Figure 5 shows the contact angle measured of CT and CT_GA_SBF_1.

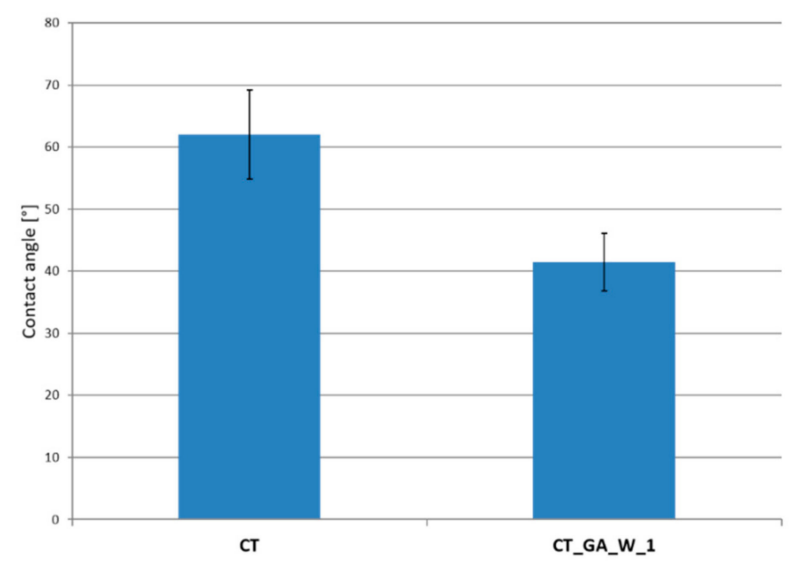

Figure 5. Contact angle measurement before and after the functionalization.

The contact angle was $62^{\circ} \pm 7^{\circ}$ for CT and $41^{\circ} \pm 5^{\circ}$ for CT_GA_SBF_1. The lowering of the contact angle value can be related to the presence of the grafted molecules of GA exposing its hydroxyl groups, as confirmed by XPS data.

\subsection{In Vitro Apatite-Forming Ability Tests}

The $\mathrm{pH}$ measurements during the soaking period highlighted a small decrease of the $\mathrm{pH}$ of the SBF solution CT_GA_SBF_1 samples during the first 3 days of soaking, probably correlated to a partial release of the grafted molecules from the surface, but also to the tendency of a portion of $\mathrm{OH}$ groups on the surfaces to dissociate into $\mathrm{H}^{+}$ions. During the further refreshes, no significant changes of the $\mathrm{pH}$ were observed.

The FESEM micrographs of the samples after 28 days in SBF are reported in Figure 6. 


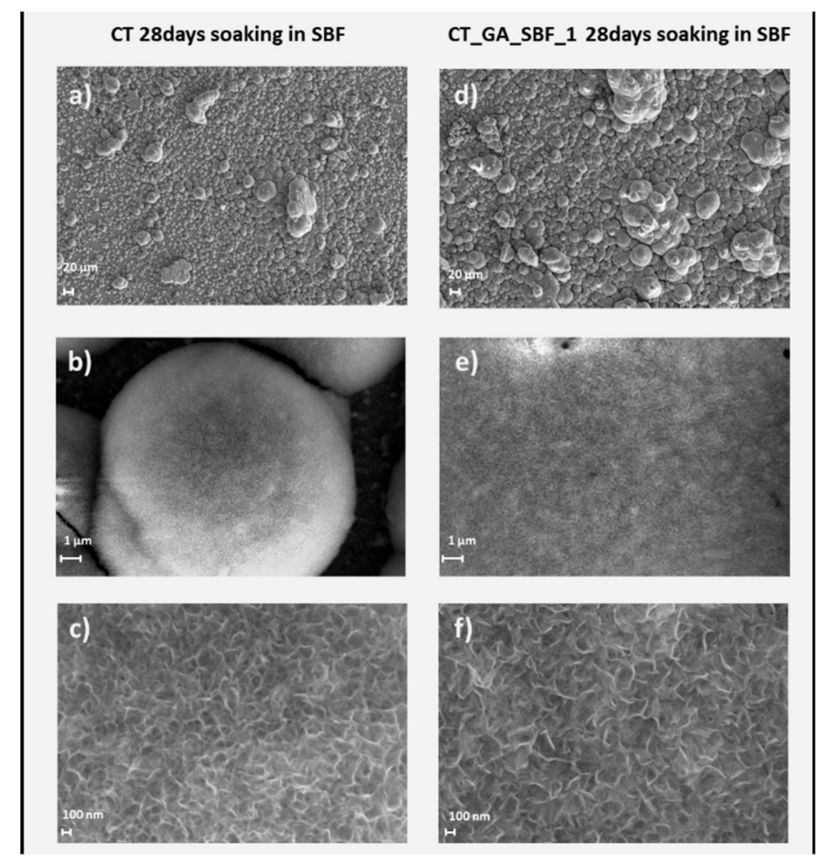

Figure 6. FESEM images of samples after 28 days SBF soaking at different magnifications. (a). (500×), (b) $(20 \mathrm{k} \times)$ and $(\mathbf{c})(100 \mathrm{k} \times)$ for CT sample, (d) $(500 \times),(\mathbf{e})(20 \mathrm{k} \times)$ and (f) $(100 \mathrm{k} \times)$ for CT_GA_SBF_1 one.

The surfaces of the functionalized and reference samples are covered by hydroxyapatite with the usual cauliflower-like morphology. The CT samples have good in vitro bioactivity as reported in a previous work [50] and on the functionalized samples the amount of grafted GA molecules did not significantly modify the bioactive behavior. In Table 4 the results of the EDS analyses performed on different areas $\left(106400 \mu \mathrm{m}^{2}\right)$ of the samples are reported.

Table 4. Atomic percentages of the elements detected on the samples by EDS survey.

\begin{tabular}{ccc}
\hline \multirow{2}{*}{ Elements (at.\%) } & \multicolumn{2}{c}{ Samples } \\
\cline { 2 - 3 } & CT & CT_GA_SBF_1 \\
\hline $\mathrm{C}$ & $7.54 \pm 3.06$ & $7.59 \pm 2.96$ \\
$\mathrm{O}$ & $55.10 \pm 10.85$ & $55.09 \pm 10.86$ \\
$\mathrm{Na}$ & $0.48 \pm 0.03$ & $0.45 \pm 0.03$ \\
$\mathrm{Mg}$ & $0.73 \pm 0.07$ & $0.75 \pm 0.07$ \\
$\mathrm{P}$ & $13.32 \pm 3.54$ & $12.71 \pm 3.37$ \\
$\mathrm{Ca}$ & $22.18 \pm 9.68$ & $22.18 \pm 9.67$ \\
$\mathrm{Ti}$ & $0.78 \pm 0.42$ & $1.25 \pm 0.67$ \\
$\mathrm{Ca} / \mathrm{P} \mathrm{ratio}$ & $1.63 \pm 0.3$ & $1.7 \pm 0.3$ \\
\hline
\end{tabular}

Calcium and phosphorus were present on the surfaces of both the samples and their ratio $(\mathrm{Ca} / \mathrm{P})$, 1.63 for CT samples and 1.70 for CT_GA_SBF_1 samples, were comparable with the stoichiometric one of hydroxyapatite (1.67) [63].

The kinetic of the hydroxyapatite formation as a function of the surface functionalization will be investigated in a further work to clarify if the ability of GA to react with calcium can affect the kinetic of bioactive behavior, besides the mechanism of grafting of the biomolecule, as discussed above. From these results it is possible to say that the functionalization did not decrease the bioactivity of the samples and further cellular tests are needed in order to understand the effects on cells. 


\subsection{Zeta Potential Measurements}

The zeta potential titration curve in function of the $\mathrm{pH}$ of the solution is reported in Figure 7 in the case of polished surfaces (reported in Figure 7 as Ti6Al4V), CT samples, CT samples soaked 28 days in SBF, CT_GA_SBF_1 samples and CT samples soaked 28 days in SBF.

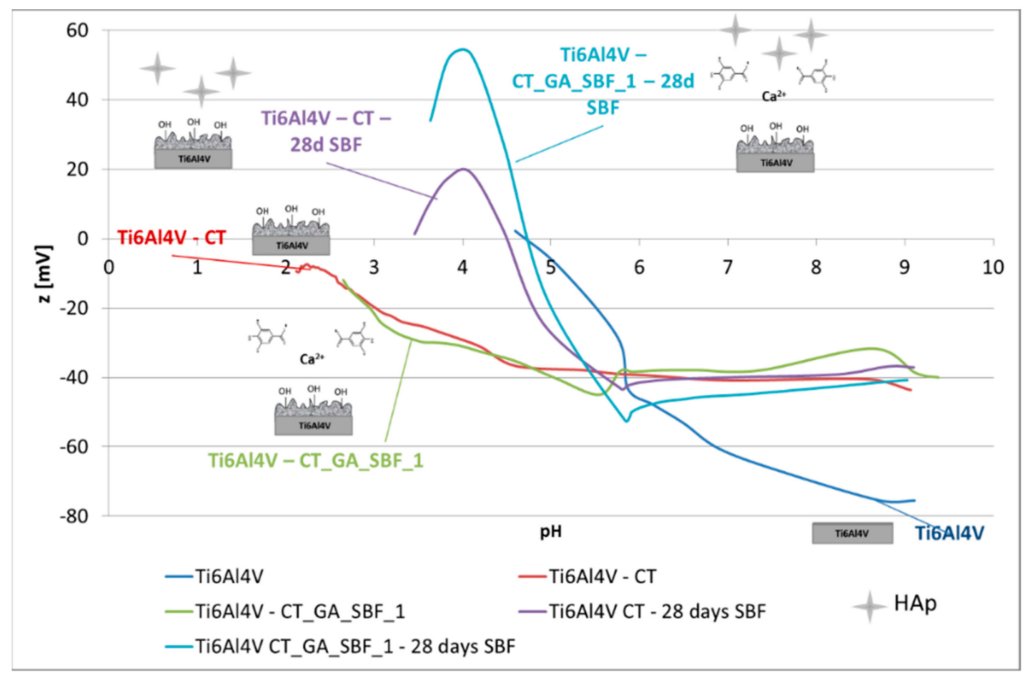

Figure 7. Zeta potential recorded as function of $\mathrm{pH}$.

Some curves show a discontinuity in the range of $\mathrm{pH}$ between $5.5-6$ and it was an artefact due to the apposition of the acid and basic sides of the titration curve which were obtained in different times, indeed if the discontinuity is lower than $10 \mathrm{mV}$, the surface alteration is considered negligible, otherwise different samples should be used for the acid and basic titrations.

An isoelectric point of 4.7 has been obtained on the polished surface, in accordance to the value reported in literature for titanium [64]. A shift of the isoelectric point to more acidic values (close to 2, extrapolating the curves in Figure 7) can be observed in the case of the CT and CT_GA_SBF_1 samples with no significant differences. The shift to a more acidic value of the isoelectric point after surface oxidation of titanium is not obvious. For instance, Kulkarni et al. [64] reported a basic shift of the isoelectric point in the case of anodized titanium (with stoichiometric titanium oxide nanotubes) compared to a titanium foil (measurement carried on the amorphous native oxide). The acidic shift of the isoelectric point here observed on the CT and CT_GA_SBF_1 samples compared to the polished surface can be attributed to the enrichment in acidic hydroxyl groups due to the presence of the chemically modified oxide layer (CT) and to the presence of GA (CT_GA_SBF_1). According to their acidic isoelectric points (2-4.7) at physiological $\mathrm{pH}$, all the considered surfaces were negatively charged, however, some differences can be pointed out between the samples. At first, a notable reduction in the absolute value of the surface charge can be observed for the CT and CT_GA_SBF_1 samples $(\approx-40 \mathrm{mV})$, compared to the polished one $(\approx-75 \mathrm{mV})$. Moreover, a plateau for the surface charge can be observed for the CT and CT_GA_SBF_1 samples and not for the polished one. This plateau can be ascribed to the presence of homogeneous chemical groups exposed on the surface, in this case acidic OH groups, as evidenced in [65], which were completely dissociated at the onset of the plateau. This result was in accordance with the acidic shift of the isoelectric points and it was a further confirmation of the presence of $\mathrm{OH}$ groups on both the CT and CT_GA_SBF_1 surfaces.

The absence of a shift of the isoelectric point (IEP) in CT_GA_SBF_1 with respect to CT was compatible with functionalization with a mono and not continuous layer, as well as to the grafting of a molecule (GA) which have an acidic isoelectric point (not far from the one of CT samples) as reported in literature for various phenolic acids [66]. 
The curve of the CT_GA_SBF_1 sample showed some distinctive features highlighting that after functionalization there is a change of the surface. There was a small plateau around $\mathrm{pH} 3-4$ that could come from partial ionization of carboxyl groups of the GA bonded to the surface [67]. There was a trend towards positive charge after $\mathrm{pH} 7.20$ with a peak around $\mathrm{pH} 8.50$ that could be connected to the degradation of gallic acid at high alkaline $\mathrm{pH}$ or to the desorption of phosphate groups adsorbed during the functionalization in the solution with SBF as medium.

In the case of the curves of the CT and CT_GA_SBF_1 samples soaked for 28 days in SBF for the apatite-forming ability tests, the IEP was moving to $\mathrm{pH} 5$ that is the IEP of hydroxyapatite [68], suggesting the presence of a continuous layer of hydroxyapatite as seen by the FESEM analysis.

Some small differences between the two curves can suggest, as reported in literature, an action of the GA on the deposition of hydroxyapatite [8,30]. In the case of the CT sample (without functionalization), the IEP was at a lower $\mathrm{pH}$ with respect to the functionalized sample and the plateau in the alkaline zone was shifted towards higher surface charge; the decreasing trend of the curve at $\mathrm{pH}$ lower than the IEP can be related to the decomposition of the hydroxyapatite layer in acidic solutions and it occurs at a lower surface charge in the case of the CT sample, similarly the peak after $\mathrm{pH} 8$ can be related to the decomposition of hydroxyapatite in the alkaline range and it occurs only in the case of the CT sample (without functionalization). All these differences could indicate the precipitation of a more stable hydroxyapatite when GA is grafted on the surface: This hypothesis needs further investigation to be proved.

\section{Conclusions}

GA was grafted to the surface of a chemically treated bioactive Ti6Al4V alloy conserving its redox activity. Surface functionalization was performed in different media (namely, water, PBS and SBF) and at different GA concentrations $(1-2 \mathrm{mg} / \mathrm{mL})$. Functionalization by using source solutions with SBF as medium proved to be the most effective in terms of molecular amount and activity; the source solution and the uptake did not show evidence of degradation; no significant difference between the use of source solutions of different concentrations was registered (in the explored range). A key role of the calcium ions in the grafting mechanism was suggested, involving coordination compounds using both carboxylate ions of $\mathrm{GA}$ and $\mathrm{Ti}^{-} \mathrm{O}^{-}$as donor groups. Bioactive behavior conferred to the titanium surface by the chemical pre-treatment was conserved after functionalization: Zeta potential measurements suggest a different kinetic of apatite precipitation, but this issue is still subjected to confirmation. The functionalized surface exposed a greater amount of $\mathrm{OH}$ groups and showed a slightly higher wettability. These preliminary results show that GA can be effectively grafted to a bioactive Ti6Al4V alloy and are promising for the development of smart metallic biomaterials able to couple the good bulk properties of the titanium alloys with both bioactive surface behavior and the biological benefits and actions of natural biomolecules, locally loaded on the surface of bone implants. The present research can be considered a preliminary study intended for the understanding functionalization mechanisms on bioactive titanium surfaces, by means of physical and chemical characterizations, using gallic acid as a model molecule for polyphenols. Considering the promising results of the present study, surface functionalization of chemically treated titanium surfaces with natural polyphenols (following the developed protocol here) and further biological characterizations should be encouraged as future developments of the work. The possibility to combine the inorganic bioactive behavior of chemically treated titanium substrates with the biological properties of natural polyphenols (antioxidant, anticancer, antibacterial, anti-inflammatory and bone stimulating) is a challenging opportunity for the development of functional biomaterials for bone contact applications in critical situations, by means of an eco-friendly and sustainable approach.

Author Contributions: Conceptualization, all the authors; Methodology M.C., S.F. and S.S.; Investigation, M.C. and S.F.; Resources, S.S.; Data Curation, all the authors; Writing-Original Draft Preparation, M.C. and S.F.; Writing-Review and Editing, E.P., V.C. and S.S.; Supervision, S.S; Software, M.C.; Validation, M.C., S.F. and S.S.; Visualization, S.F.; Project Administration, S.S. 
Funding: This research received no external funding.

Conflicts of Interest: The authors declare that they have no conflict of interest.

\section{References}

1. Pandey, K.B.; Rizvi, S.I. Plant polyphenols as dietary antioxidants in human health and disease. Oxid. Med. Cell. Longev. 2009, 2, 270-278. [CrossRef] [PubMed]

2. El Gharras, H. Polyphenols: food sources, properties and applications-A review. Int. J. Food Sci. Technol. 2009, 44, 2512-2518. [CrossRef]

3. Quideau, S.; Deffieux, D.; Douat-Casassus, C.; Pouységu, L. Plant polyphenols: Chemical properties, biological activities, and synthesis. Angew. Chem. Int. Ed. 2011, 50, 586-621. [CrossRef] [PubMed]

4. Dosier, C.R.; Erdman, C.P.; Park, J.H.; Schwartz, Z.; Boyan, B.D.; Guldberg, R.E. Resveratrol effect on osteogenic differentiation of rat and human adipose derived stem cells in a 3-D culture environment. J. Mech. Behav. Biomed. Mater. 2012, 11, 112-122. [CrossRef]

5. Li, Y.; Bäckesjö, C.M.; Haldosén, L.A.; Lindgren, U. Resveratrol inhibits proliferation and promotes apoptosis of osteosarcoma cells. Eur. J. Pharmacol. 2009, 609, 13-18. [CrossRef]

6. Đudarić, L.; Fužinac-Smojver, A.; Muhvić, D.; Giacometti, J. The role of polyphenols on bone metabolism in osteoporosis. Food Res. Int. 2015, 77, 290-298. [CrossRef]

7. Ornstrup, M.J.; Harsløf, T.; Kjær, T.N.; Langdahl, B.L.; Pedersen, S.B. Resveratrol increases bone mineral density and bone alkaline phosphatase in obese men: A randomized placebo-controlled trial. J. Clin. Endocrinol. Metab. 2014, 99, 4720-4729. [CrossRef] [PubMed]

8. Tang, B.; Yuan, H.; Cheng, L.; Zhou, X.; Huang, X.; Li, J. Effects of gallic acid on the morphology and growth of hydroxyapatite crystals. Arch. Oral Biol. 2015, 60, 167-173. [CrossRef] [PubMed]

9. Zhou, R.; Si, S.; Zhang, Q. Water-dispersible hydroxyapatite nanoparticles synthesized in aqueous solution containing grape seed extract. Appl. Surf. Sci. 2012, 258, 3578-3583. [CrossRef]

10. Saikia, J.P.; Konwarh, R.; Konwar, B.K.; Karak, N. Isolation and immobilization of Aroid polyphenol on magnetic nanoparticles: Enhancement of potency on surface immobilization. Colloids Surf. B 2013, 102, 450-456. [CrossRef] [PubMed]

11. Wang, K.; Wu, Y.; Li, H.; Li, M.; Zhang, D.; Huixia, F.; Feng, H.; Fun, H. Dual-functionalization based on combination of quercetin compound and rare earth nanoparticle. J. Rare. Earths 2013, 31, 709-714. [CrossRef]

12. Mohanty, R.K.; Thennarasu, S.; Mandal, A.B. Resveratrol stabilized gold nanoparticles enable surface loading of doxorubicin and anticancer activity. Colloids Surf. B 2014, 114, 138-143. [CrossRef]

13. Li, Y.; Dånmark, S.; Edlund, U.; Finne-Wistrand, A.; He, X.; Norgård, M.; Blomén, E.; Hultenby, K.; Andersson, G.; Lindgren, U. Resveratrol-conjugated poly-e-caprolactone facilitates in vitro mineralization and in vivo bone regeneration. Acta Biomater. 2011, 7, 751-758. [CrossRef]

14. Neo, Y.P.; Swift, S.; Ray, S.; Gizdavic-Nikolaidis, M.; Jin, J.; Perera, C.O. Evaluation of gallic acid loaded zein sub-micron electrospun fibre mats as novel active packaging materials. Food Chem. 2013, 141, 3192-3200. [CrossRef] [PubMed]

15. Ramírez-Ambrosi, M.; Caldera, F.; Trotta, F.; Berrueta, L.; Gallo, B. Encapsulation of apple polyphenols in $\beta$-CD nanosponges. J. Incl. Phenom. Macrocycl. Chem. 2014, 80, 85-92. [CrossRef]

16. Berlier, G.; Gastaldi, L.; Sapino, S.; Miletto, I.; Bottinelli, E.; Chirio, D.; Ugazio, E. MCM-41 as a useful vector for rutin topical formulations: Synthesis, characterization and testing. Int. J. Pharm. 2013, 457, 177-186. [CrossRef] [PubMed]

17. Chen, Y.; Lee, Y.D.; Vedala, H.; Allen, B.L.; Star, A. Exploring the chemical sensitivity of a carbon nanotube/green tea composite. Acs Nano 2010, 4, 6854-6862. [CrossRef]

18. Sousa, F.; Guebitz, G.M.; Kokol, V. Antimicrobial and antioxidant properties of chitosan enzymatically functionalized with flavonoids. Process Biochem. 2009, 44, 749-756. [CrossRef]

19. Božič, M.; Gorgieva, S.; Kokol, V. Homogeneous and heterogeneous methods for laccase-mediated functionalization of chitosan by tannic acid and quercetin. Carbohydr. Polym. 2012, 89, 854-864. [CrossRef] [PubMed]

20. Nunesa, C.; Maricato, É.; Cunha, Â.; Nunes, A.; da Silva, J.A.L.; Coimbra, M.A. Chitosan-caffeic acid-genipin films presenting enhanced antioxidant activity and stability in acidic media. Carbohydr. Polym. 2013, 91, $236-243$. [CrossRef] [PubMed] 
21. Trifković, K.T.; Milašinović, N.Z.; Djordjević, V.B.; Kruši, M.T.K.; Knežević-Jugović, Z.D.; Nedović, V.A.; Bugarski, B.M. Chitosan microbeads for encapsulation of thyme (Thymus serpyllum L.) polyphenols. Carbohydr. Polym. 2014, 111, 901-907. [CrossRef]

22. Moradi, M.; Tajik, H.; Rohani, S.M.R.; Oromiehie, A.R.; Malekinejad, H.; Aliakbarlu, J.; Hadian, M. Characterization of antioxidant chitosan film incorporated with Zataria multiflora Boiss essential oil and grape seed extract. LWT-Food Sci. Technol. 2012, 46, 477-484. [CrossRef]

23. Belščak-Cvitanović, A.; Stojanović, R.; Manojlović, V.; Komes, D.; Cindrić, I.J.; Nedović, V.; Bugarski, B. Encapsulation of polyphenolic antioxidants from medicinal plant extracts in alginate-chitosan system enhanced with ascorbic acid by electrostatic extrusion. Food Res. Int. 2011, 44, 1094-1101. [CrossRef]

24. Nagarajan, S.; Rami Reddy, B.S.; Tsibouklis, J. In vitro effect on cancer cells: Synthesis and preparation of polyurethane membranes for controlled delivery of curcumin. J. Biomed. Mater. Res. Part A 2011, 99, 410-417. [CrossRef]

25. Wu, H.; Wu, C.; He, Q.; Liao, X.; Shi, B. Collagen fiber with surface-grafted polyphenol as a novel support for Pd(0) nanoparticles: Synthesis, characterization and catalytic application. Mater. Sci. Eng. C 2010, 30, 770-776. [CrossRef]

26. Seshadri, S.; Sastry, T.P.; Jeevitha, D.; Samiksha, N. Synthesis and characterization of a novel bone graft material containing biphasic calcium phosphate and chitosan fortified with aloe vera. Int. J. Drug Regul. Aff. 2014, 2, 85-90.

27. Lin, F.H.; Dong, G.C.; Chen, K.S.; Jiang, G.J.; Huang, C.W.; Sun, J.S. Immobilization of Chinese herbal medicine onto the surface-modified calcium hydrogenphosphate. Biomaterials 2003, 24, 2413-2422. [CrossRef]

28. Sileika, T.S.; Barrett, D.G.; Zhang, R.; Lau, K.H.A.; Messersmith, P.B. Colorless multifunctional coatings inspired by polyphenols found in tea, chocolate, and wine. Angew. Chem. Int. Ed. 2013, 52, 10766-10770. [CrossRef] [PubMed]

29. Ferraris, S.; Zhang, X.; Prenesti, E.; Corazzari, I.; Turci, F.; Tomatis, M.; Vernè, E. Gallic acid grafting to a ferrimagnetic bioactive glass-ceramic. J. Non-Cryst. Solids 2016, 432, 167-175. [CrossRef]

30. Cazzola, M.; Corazzari, I.; Prenesti, E.; Bertone, E.; Vernè, E.; Ferraris, S. Bioactive glass coupling with natural polyphenols: Surface modification, bioactivity and anti-oxidant ability. Appl. Surf. Sci. 2016, 367, 237-248. [CrossRef]

31. Ferraris, S.; Spriano, S.; Bianchi, C.L.; Cassinelli, C.; Vernè, E. Surface modification of Ti-6Al-4 V alloy for biomineralization and specific biological response: Part II, alkaline phosphatase grafting. J. Mater. Sci. Mater. Med. 2011, 22, 1835-1842. [CrossRef] [PubMed]

32. Morra, M. Biochemical modification of titanium surfaces: Peptides and ECM proteins. Eur. Cell. Mater. 2006, 12, 1-15. [CrossRef]

33. Ferraris, S.; Spriano, S. Antibacterial titanium surfaces for medical implants. Mater. Sci. Eng. C 2016, 61, 965-978. [CrossRef] [PubMed]

34. Mohan, L.; Anandan, C.; Rajendran, N. Drug release characteristics of quercetin-loaded $\mathrm{TiO}_{2}$ nanotubes coated with chitosan. Int. J. Boil. Macromol. 2016, 93, 1633-1638. [CrossRef] [PubMed]

35. Córdoba, A.; Satué, M.; Gómez-Florit, M.; Hierro-Oliva, M.; Petzold, C.; Lyngstadaas, S.P.; Gonzales-Martin, M.L.; Monjo, M.; Ramis, J.M. Flavonoid modified surfaces: Multifunctional bioactive biomaterials with osteopromotive, anti-inflammatory and anti-fibrotic potential. Adv. Heathc. Mater. 2015, 4, 540-549. [CrossRef] [PubMed]

36. Gurzawska, K.; Svava, R.; Yihua, Y.; Haugshøj, K.B.; Dirscherl, K.; Levery, S.B.; Byg, I.; Damager, I.; Nielsen, M.W.; Jørgensen, B.; Jørgensen, N.R.; Gotfredsen, K. Osteoblastic response to pectin nanocoating on titanium surfaces. Mater. Sci. Eng. C 2014, 43, 117-125. [CrossRef]

37. Erakovic, S.; Jankovic, A.; Tsui, G.; Tang, C.Y.; Miskovic-Stankovic, V.; Stevanovic, T. Novel bioactive antimicrobial lignin containing coatings on titanium obtained by electrophoretic deposition. Int. J. Mol. Sci. 2014, 15, 12294-12322. [CrossRef]

38. Džunuzović, E.S.; Džunuzović, J.V.; Marinković, A.D.; Marinović-Cincović, M.T.; Jeremić, K.B.; Nedeljković, J.M. Influence of surface modified $\mathrm{TiO}_{2}$ nanoparticles by gallates on the properties of $\mathrm{PMMA} / \mathrm{TiO}{ }_{2}$ nanocomposites. Eur. Polym. J. 2012, 48, 1385-1393. [CrossRef]

39. Verma, S.; Singh, A.; Mishra, A. Gallic acid: Molecular rival of cancer. Environ. Toxicol. Pharmacol. 2003, 35, 473-485. [CrossRef]

40. Lu, Z.; Nie, G.; Belton, P.S.; Tang, H.; Zhao, B. Structure-activity relationship analysis of antioxidant ability and neuroprotective effect of gallic acid derivatives. Neurochem. Int. 2006, 48, 263-274. [CrossRef] 
41. ASTM B348 Standard Specification for Titanium and Titanium Alloy Bars and Billets; ASTM: West Conshohocken, PA, USA, 2010.

42. Spriano, S.; Vernè, E.; Ferraris, S. Multifunctional Titanium Surfaces for Bone Integration. EP Patent 2,214,732, 11 August 2010.

43. Ferraris, S.; Spriano, S.; Pan, G.; Venturello, A.; Bianchi, C.L.; Chiesa, R.; Faga, M.G.; Maina, G.; Vernè, E. Surface modification of Ti-6Al-4V alloy for biomineralization and specific biological response: Part I, inorganic modification. J. Mater. Sci. Mater. Med. 2011, 22, 533-545. [CrossRef]

44. Aita, H.; Hori, N.; Takeuchi, M.; Suzuki, T.; Yamada, M.; Anpo, M.; Ogawa, T. The effect of ultraviolet functionalization of titanium on integration with bone. Biomaterals 2009, 30, 1015-1025. [CrossRef]

45. Kokubo, T. Bioactive glass ceramics: Properties and applications. Biomaterials 1991, 12, 155-163. [CrossRef]

46. Singleton, V.L.; Rossi, J.A. Colorimetry of total phenolics with phosphomolybdic-phosphotungstic acid reagents. Am. J. Enol. Vitic. 1965, 16, 144-158.

47. Kokubo, T.; Takadama, H. How useful is SBF in predicting in vivo bone bioactivity? Biomaterials 2006, 27, $2907-2915$. [CrossRef] [PubMed]

48. Friedman, M.; Jürgens, H.S. Effect of $\mathrm{pH}$ on the stability of plant phenolic compounds. J. Agric. Food Chem. 2000, 48, 2101-2110. [CrossRef] [PubMed]

49. Ejima, H.; Richardson, J.J.; Liang, K.; Best, J.P.; van Koeverden, M.P.; Such, G.K.; Caruso, F. One-step assembly of coordination complexes for versatile film and particle engineering. Science 2013, 341, 154-157. [CrossRef]

50. Surleva, A.; Atanasova, P.; Kolusheva, T.; Costadinnova, L. Study of the complex equilibrium between titanium (IV) and tannic acid. J. Chem. Technol. Metall. 2014, 49, 594-600.

51. Huguenin, J.; Hamady, S.O.; Bourson, P. Monitoring deprotonation of gallic acid by Raman spectroscopy. J. Raman Spectrosc. 2015, 46, 1062-1066. [CrossRef]

52. Mera, A.C.; Contreras, D.; Escalona, N.; Mansilla, H.D. BiOI microspheres for photocatalytic degradation of gallic acid. J. Photochem. Photobiol. A 2016, 318, 71-76. [CrossRef]

53. Araujo, P.Z.; Morando, P.J.; Blesa, M.A. Interaction of catechol and gallic acid with titanium dioxide in aqueous suspensions 1. Equilibrium studies. Langmuir 2005, 21, 3470-3474. [CrossRef]

54. Ball, V.; Meyer, F. Deposition kinetics and electrochemical properties of tannic acid on gold and silica. Colloids Surf. A 2016, 491, 12-17. [CrossRef]

55. Morra, M.; Cassinelli, C.; Buzzone, G.; Carpi, A.; DiSanti, G.; Giardino, R.; Fini, M. Surface chemistry effects of topographic modification of titanium dental implant surfaces: 1. Surface analysis. Int. J. Oral Maxillofac. Implant. 2003, 18, 40-45.

56. Prajatelistia, E.; Ju, S.W.; Sanandiya, N.D.; Jun, S.H.; Ahn, J.S.; Hwang, D.S. Tunicate-inspired gallic acid/metal ion complex for instant and efficient treatment of dentin hypersensitivity. Adv. Healthc. Mater. 2016, 5, 919-927. [CrossRef]

57. Yang, Z.; Wu, J.; Wang, X.; Wang, J.; Huang, N. Inspired chemistry for a simple but highly effective immobilization of vascular endothelial growth factor on GA functionalized plasma polymerized film Plasma Process. Plasma Process. Polym. 2012, 9, 718-725. [CrossRef]

58. Qiao, G.; Su, J.; He, M. Effect of (-)-epigallocatechin gallate on electrochemical behavior and surface film composition of Co-Cr alloy used in dental restorations. Dent. Mater. J. 2012, 31, 564-574. [CrossRef]

59. Kelemen, S.R.; Rose, K.D.; Kwiatek, P.J. Carbon aromaticity based on XPS II to II* signal intensity. Appl. Surf. Sci. 1993, 64, 167-174. [CrossRef]

60. Öteyaka, M.Ö.; Chevallier, P.; Robitaillec, L.; Larocheb, G. Effect of surface modification by ammonia plasma on vascular graft: PET film and PET scaffold. Acta Phys. Pol. A 2012, 121, 125-127. [CrossRef]

61. Ferraris, S.; Venturello, A.; Miola, M.; Cochis, A.; Rimondini, L.; Spriano, S. Antibacterial and bioactive nanostructured titanium surfaces for bone integration. Appl. Surf. Sci. 2014, 311, 279-291. [CrossRef]

62. Ferraris, S.; Bobbio, A.; Miola, M.; Spriano, S. Micro- and nano-textured, hydrophilic and bioactive titanium dental implants. Surf. Coat. Technol. 2015, 276, 374-383. [CrossRef]

63. Wang, H.; Lee, J.K.; Moursi, A.; Lannutti, J.J. Ca/P ratio effects on the degradation of hydroxyapatite in vitro. J. Biomed. Mater. Res. Part A 2003, 67, 599-608. [CrossRef]

64. Kulkarni, M.; Patil-Sen, Y.; Junkar, I.; Kulkarni, C.V.; Lorenzetti, M.; Iglič, A. Wettability studies of topologically distinct titanium surfaces. Colloids Surf. B 2015, 129, 47-53. [CrossRef]

65. Luxbacher, T. The ZETA Guide: Principles of the Streaming Potential Technique; Anton Paar GmbH: Graz, Austria, 2014. 
66. Oc'wieja, M.; Adamczyk, Z.; Morga, M. Adsorption of tannic acid on polyelectrolyte monolayers determined in situ by streaming potential measurements. J. Colloid Interface Sci. 2015, 438, 249-258. [CrossRef] [PubMed]

67. Romdhane, A.; Aurousseau, M.; Guillet, A.; Mauret, E. Effect of $\mathrm{pH}$ and ionic strength on the electrical charge and particle size distribution of starch nanocrystal suspensions. Starch-Stärke 2015, 67, 319-327. [CrossRef]

68. Botelho, C.M.; LopesI, M.A.; Gibson, R.; Best, S.M.; Santos, J.D. Structural analysis of Si-substituted hydroxyapatite: Zeta potential and X-ray photoelectron spectroscopy. J. Mater. Sci. Mater. Med. 2002, 13, 1123-1127. [CrossRef] [PubMed]

(C) 2019 by the authors. Licensee MDPI, Basel, Switzerland. This article is an open access article distributed under the terms and conditions of the Creative Commons Attribution (CC BY) license (http://creativecommons.org/licenses/by/4.0/). 